\title{
Vibrio ecology, pathogenesis, and evolution
}

\section{Daniela Ceccarelli ${ }^{1 *}$ and Rita R. Colwell ${ }^{1,2 *}$}

' Department of Cell Biology and Molecular Genetics, Maryland Pathogen Research Institute, University of Maryland, College Park, MD, USA

${ }^{2}$ Department of Environmental Health Sciences, Johns Hopkins Bloomberg School of Public Health, Johns Hopkins University, Baltimore, MD, USA

*Correspondence:dcec@umd.edu; rcolwell@umiacs.umd.edu

Edited and reviewed by:

Jonathan P. Zehr, University of California, Santa Cruz, USA

Keywords: Vibrio, ecology, genome, evolution, pathogenesis

This Research Topic brings together 24 articles that highlight the most recent research findings concerning the biology of the genus Vibrio and covers pathogenicity and host interaction, genome plasticity and evolution, and the dynamics of factors influencing the ecology of vibrios.

Vibrio comprises one of the most diverse marine bacterial genera (Gomez-Gil et al., 2014), and its diversity is emphasized in two of the articles opening this set of Research Topic papers. Sawabe et al. (2013) present a molecular phylogeny of 86 Vibrio species based on genome sequencing that provides insight into Vibrio biodiversity and evolutionary history. In a study of more than 300 Vibrio genome sequences, Lukjancenko and Ussery (2014) conclude that the Vibrio pan-genome comprises 17,000 gene families, differentially present and/or expressed in any given species.

A remarkable feature of all Vibrio species is an highly plastic genome, a feature examined in five papers. The two chromosomes are shaped by horizontal gene transfer involving, among others, antibiotic resistance, virulence, and niche adaptation (RoweMagnus et al., 2001; Kirkup et al., 2010). V. vulnificus biotype 3 is a notable example. Efimov et al. (2013) suggest biotype 3 evolved from biotype 1 by acquisition of unique genes from other bacterial species, such as Shewanella, sharing the same ecological niche. Carraro et al. (2014) employ molecular and functional characterization of pVCR94, to identify the role of IncA/C plasmids in antibiotic resistance in a Rwandan V. cholerae isolate. A retrospective analysis of epidemic $V$. cholerae in Angola is reported by Valia et al. (2013), showing unexpected genomic variability among variants, highlighting the role of genomic islands, phages, and integrative conjugative elements in the genetic diversity of $V$. cholerae in a single epidemic. Rivas et al. (2013) describe acquisition by Photobacterium damselae subsp. damselae of virulence plasmid pPHDD1 that encodes pore-forming toxins and hemolysins which play a key role in virulence for both fish and humans. A review by Rapa and Labbate (2013) describes the role of integrons in Vibrio species for which gene cassettes comprise approximately $1-3 \%$ of the entire genome and are very likely involved in bacterial adaptation and evolution.

Nine of the manuscripts analyze Vibrio pathogenicity, disease development, specificity, and adaptation in both human and animal hosts. Tan et al. (2014) deciphered the biosynthetic network of the siderophore vulnibactin, essential in iron uptake from host proteins, the importance of which in $V$. vulnificus pathogenicity has been clinically demonstrated. Inhibition/resistance mechanisms developed by $V$. salmonicida, the causative agent of hemorrhagic septicemia in Atlantic salmon, is described by Bjelland et al. (2013), who show that it overcomes the salmon innate immune system to a point where the infection overwhelms the host. The role in bacterial virulence of diverse extracellular proteolytic enzymes secreted by human pathogenic Vibrio species is the focus of a review by Miyoshi (2013). The engagement of type VI secretion systems by $V$. cholerae is suggested as a means of intra- and inter-species predation and nutrient acquisition, inducing rapid multiplication in the human host (Pukatzki and Provenzano, 2013). The bioluminescent marine bacterium V. campbellii is used by Wang et al. (2013) to analyze the pyomelanin-pigmented phenotype, known to provide Vibrio species with greater UV and oxidative stress resistance and enhanced intestine colonization. The relationship between pathogenicity and motility in Vibrio species and the contribution of flagella to adhesion and biofilm formation are discussed by Zhu et al. (2013). The largely unexplored $V$. fluvialis mechanisms of pathogenesis, survival and fitness are reviewed by Ramamurthy et al. (2014). Twenty new Vibrio species associated with molluscans are described and their pathogenic potential for molluscs elucidated by Romalde et al. (2014). The exquisite bacteria-host interaction between $V$. fisheri and its squid host, Euprymna scolopes, is described in detail, as are the molecular pathways of biofilm formation, motility, and chemotaxis (Norsworthy and Visick, 2013).

The capacity of Vibrio species to persist in the aquatic environment, their ecology and association with abiotic and biotic factors, as well as environmental surveillance for public health (Lipp et al., 2002; Grimes et al., 2009; Johnson, 2013) comprise a section in the Research Topic that opens with a review by Lutz et al. (2013) elucidating complex mechanisms enabling V. cholerae to withstand starvation, temperature fluctuation, salinity variation, and predation. Haley et al. (2014) report water temperature increase can be correlated with rise of a diverse population of $V$. parahaemolyticus, some of which carry pandemic markers, in water and plankton along the Georgian coast of the Black Sea. $V$. parahaemolyticus and $V$. vulnificus populations associated with oyster, sediment, and surface water related to a hurricane event in the Chesapeake Bay are concluded to be influenced by wave energy and sediment resuspension (Shaw et al., 2014). Canesi et al. (2013) show the serum of Mytilus galloprovincialis promotes phagocytosis and killing by hemocytes of both $V$. cholerae $\mathrm{O} 1$ and non-O1/non-O139 in edible bivalves. Chakraborty et al. (2013) evaluate a sensitive and specific dipstick test to detect toxigenic $V$. cholerae in water, validating a simple, inexpensive method for use in areas at risk of cholera.

Three articles addressing Vibrio environmental diversity and dynamics complete this Research Topic. Mansergh and Zehr (2014) suggest that the natural shift of Vibrio populations in 
Monterey Bay is affected by larger oceanographic conditions (flow velocities and wind patterns), rather than individual environmental factors. Meta-analysis of environmental variables and Vibrio association with plants, algae, zooplankton, and animals are reviewed by Takemura et al. (2014). As a final point concerning environmental distribution, Constantin De Magny et al. (2014) propose temporal shifts, zooplankton community variability, and occurrence of $V$. cholerae in the aquatic environment are related to cholera dynamics. These factors, analyzed by metagenomics, permit greater understanding of community structure, function, and competition.

In summary, the collection of manuscripts provided in this Research Topic offers a comprehensive exploration of Vibrio biology, from the single gene to the bacterial community, elucidating Vibrio molecular pathways and evolutionary history. This special issue shows the significant progress achieved in understanding the complex biology of the genus Vibrio and should both stimulate discussion and offer a challenge to researchers in microbial ecology and evolution.

\section{REFERENCES}

Bjelland, A. M., Fauske, A. K., Nguyen, A., Orlien, I. E., Østgaard, I., and Sørum, H. (2013). Expression of Vibrio salmonicida virulence genes and immune response parameters in experimentally challenged Atlantic salmon (Salmo salar L.). Front. Microbiol. 4:401. doi: 10.3389/fmicf013.00401

Canesi, L., Pezzati, E., Stauder, M., Grande, C., Bavestrello, M., Papetti, A.F. (2013). Vibrio cholerae interactions with Mytilus galloprovincialis hemocytes mediated by serum components. Front. Microbiol. 4:371. doi: 10.3389/fmicb.2013.00371

Carraro, N., Sauvé, M., Matteau, D., Lauzon, G., Rodrigue, S., and Burrus, V. (2014). Development of pVCR94 $\triangle \mathrm{X}$ from Vibrio cholerae, a prototype for studying multidrug resistant IncA/C conjugative plasmids. Front. Microbiol. 5:44. doi: $10.3389 /$ fmicb.2014.00044

Chakraborty, S., Alam, M., Scobie, H. M., and Sack, D. A. (2013). Adaptation of a simple dipstick test for detection of Vibrio cholerae $\mathrm{O} 1$ and $\mathrm{O} 139$ in environmental water. Front. Microbiol. 4:320. doi: 10.3389/fmicb.2013.00320

Constantin De Magny, G., Hasan, N. A., and Roche, B. (2014). How community ecology can improve our understanding of cholera dynamics. Front. Microbiol. 5:137. doi: $10.3389 /$ fmicb.2014.00137

Efimov, V., Danin-Poleg, Y., Raz, N., Elgavish, S., Linetsky, A., and Kashi, Y. (2013). Insight into the evolution of Vibrio vulnificus biotype 3's genome. Front. Microbiol. 4:393. doi: 10.3389/fmicb.2013.00393

Gomez-Gil, B., Thompson, C. C., Matsumura, Y., Sawabe, T., Iida, T., Christen, R., et al. (2014). "Family Vibrionaceae (Chapter 225)," in The Prokaryotes, 4th Edn., eds E. Rosenberg, E. DeLong, F. L. Thonpson, S. Lory, and E. Stackebrandt (New York, NY:Springer), 88.

Grimes, D. J., Johnson, C. N., Dillon, K. S., Flowers, A. R., Noriea, N. F. 3rd., and Berutti, T. (2009). What genomic sequence information has revealed about Vibrio ecology in the ocean-a review. Microb. Ecol. 58, 447-460. doi: 10.1007/s00248-009-9578-9

Haley, B. J., Kokashvili, T., Tskshvediani, A., Janelidze, N., Mitaishvili, N., Grim, C. J., et al. (2014). Molecular diversity and predictability of Vibrio parahaemolyticus along the Georgian coastal zone of the Black Sea. Front. Microbiol. 5:45. doi: $10.3389 /$ fmicb.2014.00045

Johnson, C. N. (2013). Fitness factors in Vibrios: a mini-review. Microb. Ecol. 65, 826-851. doi: 10.1007/s00248-012-0168

Kirkup, B. C. Jr., Chang, L., Chang, S., Gevers, D., and Polz, M. F. (2010). Vibrio chromosomes share common history. BMC Microbiol. 10:137. doi: 10.1186/1471-2180-10-137

Lipp, E. K., Huq, A., and Colwell, R. R. (2002). Effects of global climate on infectious disease: the cholera model. Clin. Microbiol. Rev. 15, 757-770. doi: 10.1128/CMR.15.4.757-770.2002

Lukjancenko, O., and Ussery, D. W. (2014). Chromosome-specific families in Vibrio genomes. Front. Microbiol. 5:73. doi: 10.3389/fmicb.2014.00073

Lutz, C., Erken, M., Noorian, P., Sun, S., and McDougald, D. (2013). Environmental reservoirs and mechanisms of persistence of Vibrio cholerae. Front. Microbiol. 4:375. doi: 10.3389/fmicb.2013.00375
Mansergh, S., and Zehr, J. (2014). Vibrio diversity and dynamics in the Monterey Bay upwelling region. Front. Microbiol. 5:48. doi: 10.3389/fmicb.2014. 00048

Miyoshi, S. (2013). Extracellular proteolytic enzymes produced by human pathogenic Vibrio species. Front. Microbiol. 4:339. doi: 10.3389/fmicb.2013.00339

Norsworthy, A. N., and Visick, K. L. (2013). Gimme shelter: how Vibrio fischeri successfully navigates an animal's multiple environments. Front. Microbiol. 4:356. doi: $10.3389 /$ fmicb. 2013.00356

Pukatzki, S., and Provenzano, D. (2013). Vibrio cholerae as a predator: lessons from evolutionary principles. Front. Microbiol. 4:384. doi: 10.3389/fmicb.2013. 00384

Ramamurthy, T., Chowdhury, G., Pazhani, G. P., and Shinoda, S. (2014). Vibrio fluvialis: an emerging pathogen. Front. Microbiol. 5:91. doi: 10.3389/fmicb.2014.00091

Rapa, R. A., and Labbate, M. (2013). The function of integron-associated genes cassettes in Vibrio species: the tip of the iceberg. Front. Microbiol. 4:385. doi: 10.3389/fmicb.2013.00385

Rivas, A. J., Lemos, M. L., and Osorio, C. R. (2013). Photobacterium damselae subsp. damselae, a bacterium pathogenic for marine animals and humans. Front. Microbiol. 4:283. doi: 10.3389/fmicb.2013.00283

Romalde, J. L., Diéguez, A. L., Lasa, A., and Balboa, S. (2014). New Vibrio species associated to molluscan microbiota: a review. Front. Microbiol. 4:413. doi: 10.3389/fmicb.2013.00413

Rowe-Magnus, D. A., Guerout, A. M., Ploncard, P., Dychinco, B., Davies, J., and Mazel, D. (2001). The evolutionary history of chromosomal super-integrons provides an ancestry for multiresistant integrons. Proc. Natl. Acad. Sci. U.S.A. 98, 652-627. doi: 10.1073/pnas.98.2.652

Sawabe, T., Ogura, Y., Matsumura, Y., Gao, F., Amin, A. R., Mino, S., et al. (2013). Updating the Vibrio clades defined by multilocus sequence phylogeny: proposal of eight new clades, and the description of Vibrio tritonius sp. nov. Front. Microbiol. 4:414. doi: 10.3389/fmicb.2013.00414

Shaw, K. S., Jacobs, J. M., and Crump, B. C. (2014). Impact of hurricane irene on vibrio vulnificus and vibrio parahaemolyticus concentrations in surface water, sediment and cultured oysters in the Chesapeake Bay, Maryland, USA. Front. Microbiol. 5:204. doi: 10.3389/fmicb.2014.00204

Takemura, A. F., Chien, D. M., and Polz, M. F. (2014). Associations and dynamics of Vibrionaceae in the environment, from the genus to the population level. Front. Microbiol. 5:38. doi: 10.3389/fmicb.2014.00038

Tan, W., Verma, V., Jeong, K., Kim, S. Y., Jung, C.-H., Lee, S. E., et al. (2014). Molecular characterization of vulnibactin biosynthesis in Vibrio vulnificus indicates the existence of an alternative siderophore. Front. Microbiol. 5:1. doi: 10.3389/fmicb.2014.00001

Valia, R., Taviani, E., Spagnoletti, M., Ceccarelli, D., Cappuccinelli, P., and Colombo, M. M. (2013). Vibrio cholerae O1 epidemic variants in Angola: a retrospective study between 1992 and 2006. Front. Microbiol. 4:354. doi: 10.3389/fmicb.2013.00354

Wang, Z., Lin, B., Mostaghim, A., Rubin, R. A., Glaser, E. R., Mittraparp-Arthorn, P., et al. (2013). Vibrio campbellii hmgA-mediated pyomelanization impairs quorum sensing, virulence and cellular fitness. Front. Microbiol. 4:379. doi: $10.3389 /$ fmicb.2013.00379

Zhu, S., Kojima, S., and Homma, M. (2013). Structure, gene regulation and environmental response of flagella in Vibrio. Front. Microbiol. 4:410. doi: $10.3389 /$ fmicb.2013.00410

Conflict of Interest Statement: The authors declare that the research was conducted in the absence of any commercial or financial relationships that could be construed as a potential conflict of interest.

Received: 01 May 2014; accepted: 10 May 2014; published online: 28 May 2014.

Citation: Ceccarelli D and Colwell RR (2014) Vibrio ecology, pathogenesis, and evolution. Front. Microbiol. 5:256. doi: 10.3389/fmicb.2014.00256

This article was submitted to Aquatic Microbiology, a section of the journal Frontiers in Microbiology.

Copyright $\odot 2014$ Ceccarelli and Colwell. This is an open-access article distributed under the terms of the Creative Commons Attribution License (CC BY). The use, distribution or reproduction in other forums is permitted, provided the original author(s) or licensor are credited and that the original publication in this journal is cited, in accordance with accepted academic practice. No use, distribution or reproduction is permitted which does not comply with these terms. 